\title{
Appropriation Of Wearable Augmented Reality
}

\section{Niek Zuidhof, MSc}

Saxion University of Applied

Sciences

The Netherlands

e.n.zuidhof@saxion.nl

Dr. Somaya Ben Allouch

Saxion University of Applied

Sciences

The Netherlands

s.benallouch@saxion.nl

\section{Dr. Oscar Peters}

Newcom Research \& Consultancy

The Netherlands

o.peters@newcom.nl

Permission to make digital or hard copies of part or all of this work for personal or classroom use is granted without fee provided that copies are not made or distributed for profit or commercial advantage and that copies bear this notice and the full citation on the first page. Copyrights for third-party components of this work must be honored. For all other uses, contact the Owner/Author.

MobileHCI '18 Adjunct, September 3-6, 2018, Barcelona, Spain (c) 2018 Copyright is held by the owner/author(s).

ACM ISBN 978-1-4503-5941-2/18/09.

https://doi.org/10.1145/3236112.3236182
Prof. Dr. Peter-Paul Verbeek

e Netherlands

p.p.c.c.verbeek@utwente.nl 


\section{Good Utilization of the Side Bar}

Preparation: Do not change the text box size or position. Do copy text box to other pages. You may change the surrounding box to be visible or invisible, up to you.

Materials: This cannot appear higher or lower on the page because of pagination and specific headers added during the indexing and pagination process. A 0.75 inch rule is beneficial to break this apart from the body text. The text in this text box should remain the same size as the Body Text: 8.5 Verdana or Arial (with use of bold and italics to highlight points)

Images \& Figures: Images and figures can be placed in this section. They should be captioned in the manner of other images and figures.

\section{Research approach}

Head Mounted Displays (HMDs) are received with mixed reactions so far. Some research is done with HMDs with surgery [10] and children with autism [7]. Google Glass however, as being a specific type of HMD, caused a stir. People thought they were being recorded by a user [5], another user was attacked [9] and rules for not being a 'Glasshole' were published [4]. These reactions raise questions to the appropriation of HMDs. Researchers have developed models based on the Theory of Planned Behavior [1] to explain individuals adoption and usage up to $50 \%[2,3,12]$. In contrast to the original Social Cognitive Theory, current adoption models lack reciprocity and interaction loops. Second, these models were not designed to explain adoption of HMDs and were developed for technologies which were already widespread such as computers in organizations in the 80s. Rejection of HMDs is an important topic as well because "misalignment between explicit or implicit product capabilities affect the overall acceptance" [8]. The mediation theory $[6,13]$ can be complementary to the more often used adoption theories because technology is seen as a mediator between the user and the world and acknowledges interaction and reciprocity, implicit and explicit capabilities of the technology and ethical and social implications are included as well.

\section{Research goals}

The combination of adoption (if someone wants to use it) and mediation (how someone wants to use it) will result in a new model of appropriation of technology. The contribution of the present study is threefold: examine the perceptions of Dutch people towards HMDs, examine user interaction of HMDs and combine multidisciplinary perspectives to understand and predict adoption and use of HMDs. We argue that the integration of these theories will provide a more holistic view on appropriation of HMDs which can also be of benefit for designers and developers of these technologies.

\section{Research questions}

This dissertation focuses on the key research question: What are the influences of technology adoption and mediation of technology on the appropriation of wearable augmented reality? The sub research questions are RQ1: What are the perceived expectations of the adoption and use of wearable augmented reality? RQ2: What are users interactions anticipating the adoption and use of wearable augmented reality? RQ3: How do users evaluate the interactions of wearable augmented reality?

\section{Research studies}

The first study consisted of a survey about anticipated adoption of consumer HMDs. This was based on TAM [11] and UTAUT [12], translated in Dutch and pretested. Respondents were graduate students ( $N=100$, response rate $21 \%$ ). First results on the anticipated adoption of students of HMDs indicate that the intention to use [12] is $54 \%$. While further analyses will be conducted in the upcoming months, the results will be used as input for a pre-study for a longitudinal quantitative study of adoption. Currently, a content analysis of YouTube comments to HMDs is being conducted to get more insight into the qualitative aspects of the social meaning of people attached to HMDs. Future work will be further presented in the biography (appendix I). 


\section{References}

1. Icek Ajzen. 1991. The Theory of Planned Behavior.

Organizational Behavior and Human Decision 50,

2: 179-211.

2. Fred D. Davis. 2014. Information Technology Introduction. 13, 3: 319-340.

3. Fred D. Davis, Richard P. Bagozzi, and Paul R. Warshaw. 1989. User Acceptance of Computer Technology: A Comparison of Two Theoretical Models. Management Science 35: 982-1003.

4. Google. 2014. Explorers. Retrieved from https://sites.google.com/site/glasscomms/glassexplorers.

5. Mat Honan. 2013. I, glasshole: my year with google glass. Retrieved from

http://www.wired.com/2013/12/glasshole/.

6. Don Ihde. 1993. Philosophy of technology: an introduction. In Paragon House, New York.

7. Neha U. Keshav, Joseph P. Salisbury, Arshya Vahabzadeh, and Ned T. Sahin. 2017. Social Communication Coaching Smartglasses: Well Tolerated in a Diverse Sample of Children and Adults With Autism. JMIR mHealth and uHealth 5, 9: e140.

8. Aylin Koca, Evangelos Karapanos, and Aarnout C. Brombacher. 2009. "Broken expectations" from a global business perspective. Conference on Human Factors in Computing Systems - Proceedings: 4267-4272.

9. Noorin Ladhani. 2014. The social implications of wearable tech. Social Policy. Retrieved from http://web.a.ebscohost.com.han4wsf.saxion.nl/eho st/pdfviewer/pdfviewer?sid=99191458-36a8-4632 b36fccbb833bd3a0@sessionmgr4001\&vid=12\&hid $=419$.
10. Charles Templeman, Francisco J. O. Morales, Andrew Symes, and Daniel Roggen. 2016. Exploring glass as a novel method for hands-free data entry in flexible cystoscopy. UbiComp: $581-$ 592.

11. Viswanath Venkatesh. 2008. Technology Acceptance Model 3and a Research Agenda on Interventions. Decision Sciences 39.

12. Viswanath Venkatesh, Michael G. Morris, Gordon B. Davis, and Fred D. Davis. 2003. User Acceptance of Information Technology: Toward a Unified View. 27, 3: 425-478.

13. Peter-Paul Verbeek. 2015. Beyond Interaction : A Short Introduction to Mediation Theory. Interactions ACM: 26-31. 